УДК 1(510) + 294.3 (510)

DOI: 10.18101/1994-0866-2019-4-25-31

\title{
ЧАНЬСКИЙ КОМПЕНДИУМ «СОБРАНИЯ ИЗ ЗАЛА ПАТРИАРХОВ» («ЦЗУ ТАН ЦЗИ») О ХАНЬ ЮЕ
}

\section{(C) Мазур Татьяна Геннадьевна}

кандидат философских наук, доцент,

Институт монголоведения, буддологии и тибетологии СО РАН

Россия, 670047, г. Улан-Удэ, ул. Сахьяновой, 6

E-mail: mtbi@yandex.ru

В работе анализируются притчи (гунъани), посвященные описанию взаимоотношений чиновника-конфуцианца эпохи Тан Хань Юя и чаньского наставника Да-дяня, которые входят в сборник чаньских юйлу «Собрания из зала патриархов» («Цзу тан цзи»). Показано, что отношения Хань Юя и Да-дяня в трактовке чаньских составителей юйлу - это прецедентная история духовного развития чиновника-конфуцианца на пути его превращения в последователя буддизма, необходимая чань-буддистам прежде всего как средство воспитания и обучения монахов. В то же время показано, что несмотря на то, что сведения, содержащиеся в чаньских юйлу, не все аутентичны и являются чаньской трактовкой событий, гунъани предоставляют дополнительный материал, позволяющий судить о том, как существовала буддийская религия в танском обществе на уровне отдельного индивида. Делается вывод о том, что что в эпоху Тан буддизм охватил своим влиянием достаточно широкие слои населения, поскольку независимо от сословной принадлежности на индивидуальном уровне любой мог приобщиться к буддизму.

Ключевые слова: буддизм; школа Чань; конфуцианство; эпоха Тан; Хань Юй; общество; религия; межкультурное взаимодействие; юйлу; гунъань.

\section{Для цитирования}

Мазур T. Г. Чаньский компендиум «Собрания из зала патриархов» («Цзу тан цзи») о Хань Юе // Вестник Бурятского государственного университета. Философия. 2019. Вып. 4. С. 25-31.

«Собрания из зала патриархов» («Цзу тан цзи») является исторически первым сборником чаньских юйлу, впервые охватившим биографии китайских мастеров Чань, а не индийских, как это было ранее. Считается, что этот сборник был составлен в 952 г. чаньским монахом Цзиньсюем, и в 1004 г. вошел в классическое собрание «Записи о передаче светильника» («Цзиньдэ чуаньдэн лу») - одно из самых знаменитых произведений чань-буддизма и самое большое собрание чаньских юйлу, включившее в себя краткие биографии, диалоги и высказывания 1701 чаньского наставника и охватившее 52 поколения чаньских учителей [1, с. 42].

Интересным представляется тот факт, что в «Собраниях» содержатся сведения о чиновнике-конфуцианце эпохи Тан Хань Юе (768-824), который вошел в историю как непримиримый критик буддизма. Ему, а именно его взаимоотношениям с чаньским монахом Да-дянем, посвящено в «Собраниях» пять притч (гунъаней). Перевод этих пяти притч на английский язык представлен в работе Ч. Хартмана [2, с. 95-98]. 
Чаньский монах Да-дянь Бао-тун (732-824) - это ученик знаменитого Шитоу Си-цяня (700-790), который наряду с Цзян-си Дао-и (709-788), более известным как Ма-цзу, считался одним из наиболее влиятельных наставников школы Чань в конце VIII в. [2, с. 94; 3, с. 8$]$.

Тот факт, что Хань Юй действительно какой-то период общался с Да-дянем, подтверждается и самим Хань Юем. Так, в его литературном наследии имеется «Письмо министру Мэну» («Юй Мэн шаншу шу»), в котором Хань Юй сам повествует об этом эпизоде его жизни [4, с. 193-195; 5, с. 116-121]. Также исследователи признают аутентичными и три письма Хань Юя, адресованных Да-дяню, в которых он трижды приглашает буддийского монаха посетить его, однако эти письма дошли до нас не в полном объеме, фрагментарно, и не включаются в собрания сочинений Хань Юя [2, с. 94, с. 306; 6, с. 67-68].

Исследователи жизни и творчества Хань Юя следующим образом описывают обстоятельства его знакомства с Да-дянем. В феврале 819 г. Хань Юй подал императору записку «О кости Будды» («Лунь фогу бяо») [7, с. 151-160; 4, с. 334-335; 5, с. 30-34], в которой выразил протест против распоряжения императора доставить во дворец буддийскую реликвию - кусочек кости самого Будды - и попытался описать последствия, к которым может привести это действие. В ответ на эту записку император приказал предать Хань Юя смерти, и лишь благодаря заступничеству влиятельных друзей смертная казнь была заменена ссылкой в Чаочжоу, на юге Китая. Именно здесь, на горе Лин, недалеко от Чаочжоу, и проживал в то время чаньский монах Да-дянь [2, с. 94; 8, с. 187-190].

В «Собраниях» содержится самое детальное описание взаимоотношений Хань Юя с Да-дянем [2, с. 95]. Практически все пять притч, посвященных Хань Юю, имеют традиционную для гунъаня структуру и представляют собой беседу между наставником и учеником. Такая беседа обычно состоит из вопросов, которые задают ученики в связи с их собственной духовной практикой буддизма, и ответов наставника [3, с. 11]. В данном случае, в чаньской трактовке описываемых событий, роль наставника отводится Да-дяню, а роль ученика - Хань Юю, причем в текстах названия этих статусов вложены в уста самого Хань Юя: себя он именует «учеником», Да-дяня — «наставником».

Первая притча повествует об обстоятельствах, предшествующих знакомству Хань Юя и Да-дяня, благодаря которым оно вообще стало возможным. Согласно этой притче, Хань Юй был сослан в Чаочжоу за то, что он один из всех приближенных императора отказался признать свет, излучаемый буддийской реликвией (кусочком тела Будды), «светом Будды» ${ }^{1}$, но не смог объяснить природу этого свечения. Оказавшись в Чаочжоу, Хань Юй первым делом поинтересовался, есть ли в этой местности великие наставники Чань, и ему сразу назвали имя Да-дяня [2, c. 95-96].

Вторая притча рассказывает о том, как состоялось само знакомство Хань Юя с Да-дянем. Здесь упоминается о тех трех письмах-приглашениях, которые Хань Юй отправлял Да-дяню и которые остались без ответа. Однако говорится, что позже Да-дянь явился к Хань Юю сам, без приглашения, объяснив, что причина

\footnotetext{
${ }^{1}$ Ч. Хартман поясняет, что «Свет Будды» - это сияние, исходящее от тела и ума Будды. Это условный символ мудрости (праджня), и Да-дянь позже использует его как метафору просветления [2, с. 307].
} 
его визита — тот самый «свет Будды», который Хань Юй отказался признать. Далее идет классический чаньский диалог наставника (Да-дяня) и ученика (Хань Юя), из которого следует, что Да-дянь согласен с точкой зрения Хань Юя и также не считает то свечение «светом Будды». Однако Хань Юя интересует вопрос, что за свет все-таки видел он и все участвовавшие в церемонии встречи буддийской реликвии. Да-дянь поясняет, что «это был просто свет восьми классов магических существ или Индры, или Брахмы, помогающих распространению веры», в ответ на что Хань Юй восклицает: «Был бы тогда в столице такой человек, как Вы, Мастер, Ваш ученик не был бы сегодня здесь!» [2, с. 96].

Первая и вторая притчи, можно сказать, являются «зачином», в котором раскрывается, как вообще стало возможным общение Хань Юя и Да-дяня. Обращает на себя внимание тот факт, что в обеих из них фигурирует понятие «свет Будды», которое, по всей видимости, играет ключевую роль в деле знакомства Хань Юй с Да-дянем. Можно предположить, что составители юйлу хотели подчеркнуть тот факт, что чаньский монах обратил внимание на личность Хань Юя и согласился на общение с ним именно потому, что Хань Юй отказался видеть «свет Будды» (праджню) в чем-то материально воплощенном, опосредованном, а значит, ложном, что полностью соответствует духу школы Чань, которая не принимала эмпирическое сознание в качестве опоры для истинно сущего и считала, что истинно сущее должно постигаться непосредственно, интуитивно [9, с. 184; 10, с. 241].

Третья, четвертая и пятая притчи еще в большей степени соответствуют классической структуре гунъаня. В них Хань Юй пытается получить ответы на волнующие его вопросы, касающиеся буддизма.

Так, в третьей притче Хань Юй задает Да-дяню вопрос о том, есть ли в действительности «свет Будды». Получив утвердительный ответ, Хань Юй пытается узнать, на что похож «свет Будды» и слышит: «На вице министра!», т. е. на самого Хань Юя (именно так, посредством должности, помимо имени, в притчах обозначается личность этого персонажа), поэтому данный ответ вводит его в заблуждение. Но Да-дянь далее поясняет: «Если ты действительно поймешь это, тогда это и будет настоящий свет Будды. Ибо путь Будды - это единственный путь. Его свет ни синий, ни желтый, ни красный, ни белый. Он простирается до горы Шумеру и освещает все горы и реки на этой огромной земле; ничьи глаза не видели его, ничьи уши не слышали. Пять видов зрения не могут увидеть его форму; два вида слуха не могут услышать его звучание. Если ты познаешь этот свет Будды, тогда все святое и мирское станет иллюзией и не сможет ввести тебя в заблуждение» [2, с. 97].

В этой притче мы прежде всего имеем дело с демонстрацией буддийской идеи о наличии природы Будды в самом индивиде, присущей всем школам китайского буддизма, в особенности школе Чань. Также здесь вновь прослеживается чаньская идея о том, что истинно сущее не может быть выражено с помощью вербальных конструкций, которая реализуется в учении о «живом» и «мертвом» слове. Так, согласно чань-буддистам, «мертвое» слово - это понятие, несущее в себе определенную информацию и составляющее основу дискурсивного знания, оно искажает истинную реальность, в то время как истинная реальность все же может быть выражена в слове, если это «живое» слово, т. е. слово, высказанное просветленным сознанием [9, с. 186-187; 10, с. 243-244; 11, с. 22-27]. Кроме этого, в притче пока- 
зан и чаньский метод обучения, направленный на разрушение стереотипов обыденного сознания, предполагающий неожиданные и ошеломляющие действия и ответы наставника.

В четвертой притче Хань Юй вновь пытается в вербальных терминах постичь суть буддийского учения. Он обращается к Да-дяню: «Твой ученик очень занят военными и гражданскими делами; не может ли Мастер указать, что он считает основным в учении Будды?». Однако Да-дянь, пребывая в медитации, никак не реагирует на вопрос Хань Юя. Он долгое время сохраняет молчание, что вводит Хань Юя в замешательство. Видя это, помощник Да-дяня Сан-пин резко ударяет по скамье для медитации за спиной наставника, тот оборачивается и спрашивает: «Что?» Помощник отвечает: «Сначала человек ослабляет [страдание] через медитацию, затем он искореняет [заблуждение] через мудрость». Услышав это, Хань Юй говорит Сан-пину: «Мастер очень высоко, а ученик растерялся. Но сейчас благодаря его помощнику я понял, где вход» [2, с. 97-98]. Здесь мы снова имеем дело с демонстрацией чаньского приема разрушения стереотипов, и, как следует из притчи, этот метод обучения применительно к Хань Юю начинает давать свои плоды.

Последняя, пятая, притча является своего рода «развязкой» всей этой истории. В ней говорится о том, что Хань Юй в очередной раз совершил восхождение на гору, чтобы отдать дань уважения Да-дяню, но застал его спящим. Он подождал, пока наставник проснется, а тот, проснувшись, не поднялся к Хань Юю, а лишь спросил его: «Ты пришел [сюда], совершая восхождение в горы, или ты пришел, чтобы отдать дань уважения этому старому монаху?» Хань Юй ответил, что пришел отдать дань уважения мастеру. Да-дянь удивился и сказал: «Ну, и ты до сих пор не сделал [этого]; чего ты ждешь?» Тогда Хань Юй совершил обряд поклонения. Позже Хань Юй вновь поднялся на гору, и снова Да-дянь спросил его: «Ты пришел [сюда], совершая восхождение в горы, или ты пришел, чтобы отдать дань уважения этому старому монаху?» На этот раз Хань Юй ответил, что пришел сюда, совершая восхождение в горы. Тогда наставник спросил: «Ты пришел [сюда] с посохом для восхождения?» Хань Юй ответил, что нет. В ответ на это наставник произнес: «Если ты не принес его, значит, ты пришел пустым и тебе здесь делать нечего» [2, с. 98]. По мнению Ч. Хартмана, последние слова Да-дяня означают, что Хань Юй более не нуждается в помощи наставника для продвижения по пути Будды, точно так же, как не нуждается в посохе для восхождения в горы [2, с. 99].

Таким образом, можно сказать, что эти пять притч - это составленная чаньскими учениками поучительная история о якобы духовном развитии чиновникаконфуцианца на пути просветления и его превращении в последователя буддизма. Так, в первой и во второй притчах чаньские авторы показывают нам Хань Юя чиновника, сознание которого еще омрачено привязанностью к внешнему миру, не свободно от внешних оков, что и заставляет его раздумывать над причинами, по которым он оказался в опале, и сожалеть о произошедшем. В третьей притче перед нами уже Хань Юй, движущийся к просветлению, которого волнуют вопросы из собственной духовной практики буддизма, однако он еще не в состоянии в полной мере уяснить их, ответы наставника ставят его в тупик. В четвертой притче составители юйлу подчеркивают еще больший духовный рост Хань Юя, когда благодаря спонтанным, разрушающим стереотипы действиям наставника и его помощника к нему приходит озарение, он внезапно самостоятельно осознает, 
куда ему двигаться дальше. В пятой притче духовный рост Хань Юя отмечает уже сам наставник, и чаньские авторы рисуют нам личность, более не нуждающуюся ни в чьих наставлениях на пути к просветленному сознанию.

Содержание данных притч и само их наличие ставит ряд вопросов. Во-первых, для чего чаньским составителям юйлу понадобился такой персонаж, как Хань Юй, который, как указывалось ранее, был не только чиновником-конфуцианцем, но и рьяным критиком буддизма? И, во-вторых, насколько достоверны сведения, содержащиеся в этих притчах? Что дают они для понимания процесса распространения буддизма в Китае?

Отвечая на первый вопрос, необходимо иметь в виду, что гунъани выступали как средство воспитания и обучения монахов, помимо диалогов они включали в себя и рассказы о поступках наставников в качестве положительных примеров, и рассказы о поступках нерадивых монахов в качестве «антипримеров» [1, с. 36]. Поучительная история о том, как рьяный конфуцианец и противник буддизма якобы вступил на путь просветления, по всей видимости, должна была демонстрировать и подтверждать генеральную идею школы Чань: на пути к просветлению «нет никакой разницы, чем ты занимаешься, являешься ли монахом или мирянином, какое конкретно учение исповедуешь. Важно лишь одно - чистота твоего сердца-сознания, незатронутость его «путами мира»» [1, с. 27]. Кроме этого, не исключается и чисто социальная причина: усилить значимость своего учения, включив в круг своих адептов таких известных уже современникам критиков буддизма, как «вице министр Хань Юй».

Что касается второго вопроса о достоверности сведений, содержащихся в этих притчах, то здесь необходимо вспомнить, что дословно «гунъань» означает «общественные записи» или «общедоступные записи о типичных случаях» [1, с. 7], что это не вымышленные истории, а именно прецедентные случаи, которые записывалась учениками чаньских мастеров, их основные действующие лица - реальные исторические личности, т. е. в основе гунъаня лежит реальная история. Отсюда мы можем сделать следующие выводы. Во-первых, сам жанр юйлу свидетельствует о том, что история общения Хань Юя с чаньским монахом не вымышленная, что она действительно имела место, тем более что, как указывалось ранее, она подтверждается и другими источниками. Во-вторых, само общение Хань Юя с Да-дянем в содержательном плане, по всей видимости, все-таки было не заурядным, не мимолетным и в этом смысле прецедентным, раз оно привлекло внимание чаньских учеников. И, в-третьих, сам факт общения конфуцианца с буддийским монахом, по-видимому, уже не вызывал удивления у современников, был вполне типичным событием того времени.

В то же время надо понимать, что не все сведения, зафиксированные в гунъанях, - исторический факт. Учитывая, что многие юйлу записывались через столетия после жизни самих чаньских мастеров, в них далеко не все аутентично $[1$, c. 35-36], к тому же любая история, описанная в гунъанях, будет являться чаньской трактовкой того или иного события. Так, уже сама причина, по которой Хань Юй оказался в ссылке в Чаочжоу, интерпретируется чаньскими авторами именно в необходимом им ракурсе. Известно, что в ссылке Хань Юй оказался вследствие своей записки «О кости Будды», которую он подал на имя императора. Эта записка - острый социально-политический и социально-экономический трактат, в котором Хань Юй, как чиновник, объясняет императору, чем грозит государству 
процветание такой религии, как буддизм. Конфликт Хань Юя с императором, можно сказать, затрагивает сферу управления государством, политическую идеологию и экономическую политику, вообще не касается религиозной сферы, как это представлено в первой притче. Исходя из этого, можно предположить, что и все остальные описываемые в притчах события, в том числе и становление Хань Юя на путь просветления, несколько преувеличены чаньскими авторами и интерпретированы в нужном им свете.

Таким образом, гунъани «Собраний», описывающие отношения конфуцианца Хань Юя и чаньского монаха Да-дяня, предоставляют дополнительный материал, позволяющий судить о том, как существовала буддийская религия в танском обществе на уровне отдельного индивида. Тот факт, что персонажами юйлу в этот период являются не только чаньские наставники и их ученики, но и чиновникиконфуцианцы, свидетельствует о том, что буддизм охватил своим влиянием достаточно широкие слои населения, и независимо от сословной принадлежности на индивидуальном уровне любой мог приобщиться к буддизму.

Работа выполнена в рамках государственного задания (проект XII. 191.1.3. «Комплексное исследование религиозно-философских, историко-культурных, социально-политических аспектов буддизма в традиционных и современных контекстах России и стран Центральной и Восточной Азии», номер госрегистрации № AAAA-A17-117021310263-7)

\section{Лuтература}

1. Маслов А. А., Логинова Е. С. Лучшие притчи дзэн: обычные истории о людях необычных. Ростов н/Д.: Феникс; Краснодар: Неоглори, 2009. 342 с.

2. Hartman, Ch. Han Yü and the T'ang Search for Unity. Princeton: Princeton University Press, $1986.460 \mathrm{c}$

3. Линь-цзи лу / вступ. ст., пер. с кит., коммент. и граммат. очерк И. С. Гуревич. СПб.: Петербургское востоковедение, 2001. 272 с.

4. Хань Юй цюаньцзи. Шанхай: Шанхай гуцзи чубаньшэ. 1997. 390 с.

5. Хань Юй, Лю Цзунъюань. Избранное / пер. И. Соколовой. М.: Художественная литература, 1979. $230 \mathrm{c}$.

6. Сюй Кэ. Лунь Хань Юй юй фосэн цзяован // Хань Юй яньцзю луньвэньцзи. Гуанчжоу, 1988. С. 64-74.

7. Хань Юй ши вэнь и ши [Стихи и проза Хань Юя с переводом и комментариями] / сост. Цзоу Цзиньсянь. Харбин: Хэйлунцзян жэньминь чубаньшэ, 1985. 311 с.

8. Бянь Сяосюань, Чжан Цинхуа, Янь Ци. Хань Юй пинчжуань [Биография Хань Юя с комментариями]. Нанкин: Наньцзин дасюэ чубаньшэ, 1998. 586 с.

9. Янгутов Л. Е. Единство, тождество и гармония в философии китайского буддизма. Новосибирск: Наука, 1995. 224 с.

10. Янгутов Л. Е. Традиции Праджняпарамиты в Китае. Улан-Удэ: Изд-во Бурят. гос. ун-та, 2007. $272 \mathrm{c.}$

11. Нестеркин С. П. Концепция речи в философии чань-буддизма // Вестник Бурятского государственного университета. 2010. № 8. С. 22-27. 


\section{CHAN COMPENDIUM “THE ANTHOLOGY OF THE PATRIARCHAL HALL"} ABOUT HAN YU

\section{Tatyana G. Mazur}

Cand. Sci. (Philos.), A/Prof., Institute for Mongolian, Buddhist and Tibetan Studies SB RAS

Siberian Branch of the Russian Academy of Sciences

6 Sakhyanovoy St., Ulan-Ude 670047, Russia

E-mail: mtbi@yandex.ru

The article analyzes the parables (koans) of Chan compendium "The Anthology of the Patriarchal Hall" describing the relationship between the Confucian official of the Tang era Han $\mathrm{Yu}$ and the Chan master Dadian. It is shown that the relationship between Han Yu and Dadian in the interpretation of Chan compendium is a story of the spiritual development of the Confucian official, his becoming the follower of Buddhism - for Chan Buddhists this story is primarily a means to educate monks. At the same time, despite the fact that the data of Chan compendium are not all authentic and are not a Chan interpretation of events, the koans provide additional material on the personal perception of Buddhist religion in the Tang society. It is concluded that in the Tang era Buddhism extended over broad population, since anyone regardless his class affiliation could become the follower of Buddhism.

Keywords: Buddhism; Chan school; Confucianism; the Tang era; Han Yu; society; religion; intercultural exchange; compendiums; koan. 